\title{
THE MISSING "CYCLE" PART AND OTHER THOUGHTS ON THE GLOBAL FINANCIAL CYCLE
}

\section{OLGA BONDARENKO ${ }^{a}$}

\author{
${ }^{a}$ National Bank of Ukraine \\ E-mail: Olha_Bondarenko@bank.gov.ua
}

\begin{abstract}
The paper studies co-movement in capital flows, which gives rise to a phenomenon dubbed the global financial cycle. It first estimates a global common factor in capital flows using a factor model and draws inferences of its quantitative importance. Then the paper studies the cyclical properties of the extracted factor and concludes that, in general, its importance for capital flows is relatively limited. This may suggest that the Mundell-Fleming trilemma (as opposed to dilemma) still describes the trade-off faced by policymakers, and domestic policies play the primary role in maintaining macroeconomic stability.
\end{abstract}

JEL Codes F32, F36, F4, G15

Keywords global financial cycle, capital flows, factor model, turning points, concordance

\section{INTRODUCTION}

In recent decades, the global financial system has undergone a notable transformation. Gradual capital account liberalization since the 1970 s by advanced and emerging economies alike has led to an increase in capital flows in both size and volatility. By 2008 , global gross flows have surged from below 5 percent of world GDP during 1980-99 to almost 20 percent (IMF, 2012) while gross external liabilities more than quadrupled to $200 \%$ of GDP. Following the global financial crisis, total cross-border positions have virtually stopped growing due to the slowdown in capital flows between advanced economies, especially financial centers, but in general, the level of financial integration has remained high (Lane and Milesi-Ferretti, 2017).

Back in 1996, Calvo et al. stated, "Global factors affecting foreign investment tend to have an important cyclical component, which has given rise to repeated booms and busts in capital inflows". Yet the notion of a "global financial cycle" gained its popularity only at the outbreak of the 2008-09 crisis: during this period, the number of references in the media tripled compared to 2007. Since then, the concept has become an important aspect of monetary or macroprudential policy discussions (Borio, 2019).

Its most popular definition comes from an influential paper by Rey (2015), according to which "global financial cycles are associated with surges and retrenchments in capital flows, booms and busts in asset prices and crises [... and] characterized by large common movements in asset prices, gross flows, and leverage". Building upon this statement, in this paper the global financial cycle is defined as an unobservable common component that reflects alternating peaks and troughs in gross capital flows across a broad sample of countries. Given that the paper is in essence devoted to this single topic, the terms "global financial cycle", "global cycle", as well as "global factor" might be used interchangeably throughout the study.

The existence of a powerful common cycle in capital flows and financial market prices constitutes an issue for policymakers. The classic Mundell-Fleming trilemma states that a flexible exchange rate allows for monetary policy independence when a capital account is open. In the presence of the global financial cycle, however, this does not hold true. If capital flows to and from a particular small open economy are well synchronized with the cycle, domestic financial conditions become aligned with global ones. Therefore, the trilemma turns into a dilemma: either to liberalize the financial account or pursue an independent monetary policy. Meanwhile, the choice of an exchange rate regime becomes irrelevant (Rey, 2015).

On the contrary, if the global cycle fails to explain developments in capital flows, traditional approaches to maintaining macro-financial stability remain appropriate. Hence, from a policymaking perspective, the question is not only "if the global financial cycle exists," but also "to what extent capital flows in and out of the country are dancing to the tune of the global cycle."

While economic literature generally gives an affirmative answer to the first of the aforementioned questions, it has not yet reached a persuasive conclusion on the quantitative importance of the global financial cycle for capital flows. Using a factor model, Barrot and Serven (2018) estimate that the global factor accounts on average for almost $40 \%$ of the 
variance of capital inflows to developed countries and about $15 \%$ to emerging market countries. Borio (2019) provides similar, but slightly lower figures: $30 \%$ and $8 \%$, respectively. Instead, Cerutti, Claessens, and Rose (2017) find that, with some exceptions, the global factor explains up to $25 \%$ of volatility in capital flows, and on average - only $5 \%$.

Although differences in methodology, country sample, and period are obvious candidates for the source of discrepancy in estimates, this paper explicitly shows that results of factor models are significantly influenced by data frequency and level of aggregation. Using an identical model setup and panel data, it finds that, on average, the share of variance explained varies from $25 \%$ for the most aggregated data to $7 \%$ for the least aggregated data.

Moreover, it might be important to separate the notion of synchronization from the share of variance explained. The latter takes into account not only a direction, but also a magnitude of change in capital flows. If the magnitude varies from cycle to cycle, this variance explained may appear to be an imperfect measure of synchronization. To check whether this holds, this paper computes the concordance index - a non-parametric measure of alignment between cycles - and test its significance. As is shown further, some capital flows generally share expansion and contraction phases with the global factor, but it explains only a small portion of volatility in these flows. The paper also documents some basic properties of the observed cycles.

The paper is structured as follows. Section 2 provides a short review of buoyant literature on the global financial cycle. Section 3 describes a dataset. Section 4 shows the results of the "traditional" factor model. Section 5 presents an analysis of turning points. Section 6 concludes.

\section{LITERATURE REVIEW}

Earlier literature analyzes capital flows through the lens of "push" and "pull" factors, where the former refer to conditions in a source country while the latter - in a recipient country. Starting with the works by Fernandez-Arias (1996) and Calvo et al. (1993), this framework was mostly devoted to explaining the drivers of capital inflows into emerging markets. Researchers have been choosing a limited number of variables to explain developments in capital flows. The pool of "global factors" contains predominantly, but not exclusively, indicators of risk aversion (VIX) and interest rates in advanced economies (the U.S.). Summarizing an extensive review of 40 empirical studies on the topic, Koepke (2015) states that these factors have the largest impact on portfolio flows, and somewhat less - on banking (other) flows. Global risk aversion is also found to play an important role in extreme capital flow episodes, such as surges and stops (Forbes and Warnock, 2012; Ghosh et al., 2014).

On the contrary, recent literature concentrates on an "alternative" approach - to extract a single factor from capital flows and compare it to observable variables, e.g. the VIX. Given the availability of large panel datasets, factor models turned out to be an appealing and simple framework for the analysis. Starting with Rey (2015), researchers have pointed to a strong commonality in gross capital inflows and outflows, which is a precondition to fit a factor model.
Barrot and Serven (2018) estimate a two-level latent factor model on annual flows from three groups of countries - advanced, emerging, and developing. They find that the global factor explains about $38 \%$ and $47 \%$ of the variance of inflows and outflows in advanced economies, while in emerging markets - just $15 \%$ and 25\%, respectively. The authors also confirm that global factors are related to traditional "push" variables: $70-80 \%$ of volatility is due to the VIX, U.S. interest rates, the U.S. real exchange rate, U.S. real GDP growth, and world commodity prices.

In turn, Cerutti et al. (2017) estimate a bunch of factor models on quarterly data and apply a range of techniques to quantify the importance of the global cycle. Still, they wrap up the paper stating that $25 \%$ is an approximate upper bound on the estimates of a share of volatility explained by a single common factor.

Davis et al. (2019) consider an impact of global factors both on gross and net capital flows with a classical static setup and annual aggregate data. They identify two significant factors - the global financial cycle and the commodity price factor - which account for about $40 \%$ of the variance of gross and net capital flows. The authors also replicate their analysis using quarterly data and find that their results change quantitatively (on average, the share of volatility due to these factors reduces to $25 \%$ ), but not qualitatively.

This paper generally fits this strand of literature. It documents divergences in the standard measure of the quantitative importance of the global cycle for capital flows and points to the presence of qualitative divergences as well. Next, the paper departs somewhat from a traditional approach and attempts to elaborate upon the cyclical properties of the variable termed "cycle". To do this, it relies on an analysis of turning points. This method is rarely used in the global financial cycle literature (the only example found is Reinhart et al., 2017), but is rather common in the determining domestic financial cycles (e.g., Drehmann et al, 2012; Claessens et al. 2011, 2012; Schuler et al., 2015).

\section{DATA}

A dataset is constructed using the IMF's International Financial Statistics and World Economic Outlook databases. Capital flows vis-à-vis the rest of the world are subdivided first into two broad categories: a) inflows, i.e. purchases of domestic assets by foreign residents, and b) outflows, or purchases of foreign assets by domestic residents. In accounting terms, both inflows and outflows are presented on a net basis in the financial account (incurrence of liabilities and acquisition of financial assets) but are commonly referred to as "gross" in the literature and this paper. These gross flows are further split into direct investments, portfolio equity, portfolio debt, and other investments. All measures exclude exceptional financing and are normalized by the trend of the country's GDP (at a respective frequency). ${ }^{1}$

The dataset comprises four balanced panels of annual and quarterly flows spanning 20 years, from 1999 to 2019. It covers a broad range of countries - 17 advanced economies (AE) and 33 emerging markets (EM), as reported 
in Table 2 - but excludes financial centers, as defined in Lane and Milesi-Ferretti (2017).

Descriptive statistics are provided in Table 3. As data contains outliers, the reported values are medians of selected descriptive statistics. Compared to EM countries, advanced economies receive larger capital inflows of all types, except for direct investment, and post higher outflows. This tendency is evident from both annual and quarterly data, as measures of central tendency are generally equivalent in these two sets. On the contrary, the standard deviation is about twice higher in quarterly data so that flows appear more volatile. In line with previous findings by Broner et al. (2013), inflows and outflows are correlated; yet, in annual data, correlation is higher. Figures 1 and 2 illustrate some of the above-mentioned facts.

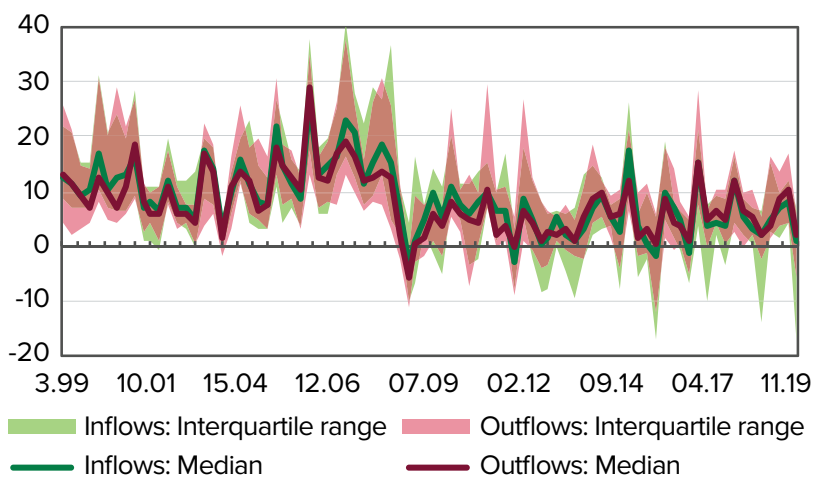

Figure 1. Aggregate Inflows and Outflows in AE Sources: own elaboration, based on IFS data.

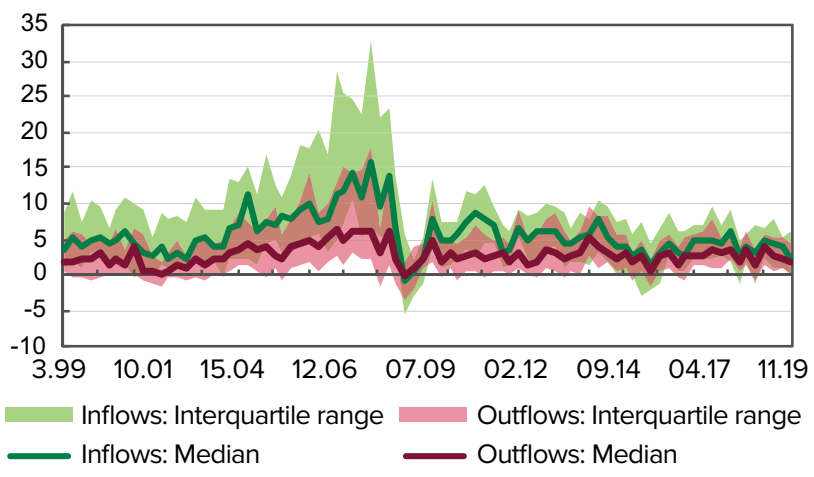

Figure 2. Aggregate Inflows and Outflows in EM Sources: own elaboration, based on IFS data.

To improve the comparability of data, the paper expresses quarterly flows as a four-quarter moving average. This transformation significantly reduces (but not eliminates) within-year volatility, as shown in Table 4, while the standard deviation becomes closer to the respective value in the annual data.

The final point touches upon the stationarity of data. The results of the Augmented Dickey-Fuller tests how that $60 \%$ of annual and $22 \%$ of quarterly (untransformed) capital flows are nonstationary. ${ }^{2}$

\section{FACTOR MODEL}

As was already mentioned, the estimation of a factor model is the most popular approach to extract the global cycle from either capital flows or asset prices. In essence, it attempts to explain co-movement in a vector $\mathbf{x}_{\mathbf{t}}$, containing a large number of variables, with a few common factors. For the sake of completeness, this paper includes some theoretical background of the factor models using large $N \rightarrow \infty$ data, the so-called approximate factor models. In its simplest form, it expresses any standardized capital flow $x_{i, t}$ as.

$$
x_{i, t}=\lambda_{i} \mathbf{F}_{\mathrm{t}}+\varepsilon_{i, t},
$$

where $F_{t}$ is a vector of unobserved common factors, $\lambda_{i}$ contains respective factor loadings, and $\varepsilon_{i, t}$ is an idiosyncratic component, capturing flow-specific dynamics. The term $\lambda_{i} F_{t}$ represent a common component of the model.

The principal component analysis (PCA) is a traditional method to estimate an approximate factor model. It decomposes $N \times N$ covariance matrix $\Sigma_{X}$ of $\mathrm{x}_{\mathrm{t}}$ into.

$$
\Sigma_{X}=\Lambda \Sigma_{f} \Lambda^{\prime}+\Sigma_{\varepsilon}
$$

by minimizing the sum of variances of the idiosyncratic terms. Intuitively, the higher the correlation between the series along one particular dimension (or the less spread is the data around an eigenvector for a principal component, describing that dimension), the higher portion of variance will be explained by that component. ${ }^{3}$ The setup also allows for mild serial and cross-sectional correlation in $\Sigma_{\varepsilon}$, i.e. for nonzero non-diagonal elements, which is typically observed in macroeconomic data.

Note, that as both loadings and factors are unobservable and not separately identifiable, restrictions should be imposed on the matrix of loadings $\Lambda$ and factors $F$. The PCA method implies that factors are orthogonal and have unit variance, $\Sigma_{f}=I$, and $\Lambda^{\prime} \Lambda$ is diagonal with distinct, decreasing diagonal elements (Lutkepohl, 2014). It turns Equation 2 into

$$
\Sigma_{X}=\Lambda \Lambda^{\prime}+\Sigma_{\varepsilon}=\Sigma_{\lambda}+\Sigma_{\varepsilon}
$$

Since variables in $x_{t}$ are standardized to have zero mean and unit variance, the covariance matrix $\Sigma_{X}$ is in essence a correlation matrix. Table 1 reports average pairwise correlations and shares of significant correlations in capital inflows by type (Table 5 - for outflows). ${ }^{4}$ All values are positive, which is in line with previous findings and generally confirms the existence of a common component in capital flows. Nevertheless, the share of significant correlations rarely exceeds $25 \%$, possibly pointing to a quite heterogeneous data. In absolute terms, the correlation between aggregated flows is higher than between specific types of investments, and even more so if quarterly data is used.

\footnotetext{
${ }^{2}$ The number of lags was determined by AIC with a maximum of 4 for annual data and 24 for quarterly.

${ }^{3}$ For derivations the reader is referred to, for example, Barigozzi (2018).

${ }^{4}$ The t-statistic for the correlation coefficient is calculated as $t_{c o r r}=\frac{r \sqrt{n-2}}{\sqrt{1-r^{2}}}$, where $\mathrm{r}$ is a correlation coefficient, and $\mathrm{n}$ is a length of series.
} 
Table 1. Unweighted Averages of Bilateral Correlation Coefficients* of Capital Inflows and Percentages of Significant Correlations

\begin{tabular}{|c|c|c|c|c|c|c|c|c|c|c|}
\hline \multicolumn{11}{|c|}{ Annual } \\
\hline & \multicolumn{2}{|c|}{ Aggregate flows } & \multicolumn{2}{|c|}{ Direct investment } & \multicolumn{2}{|c|}{$\begin{array}{c}\text { Portfolio } \\
\text { investment: Equity }\end{array}$} & \multicolumn{2}{|c|}{$\begin{array}{c}\text { Portfolio } \\
\text { investment: Debt }\end{array}$} & \multicolumn{2}{|c|}{ Other investment } \\
\hline & Corr. & Sign. & Corr. & Sign. & Corr. & Sign. & Corr. & Sign. & Corr. & Sign. \\
\hline Full sample & 21.6 & $19 \%$ & 13.3 & $12 \%$ & 10.0 & $16 \%$ & 10.0 & $10 \%$ & 16.0 & $15 \%$ \\
\hline$A E$ & 21.1 & $17 \%$ & 9.1 & $11 \%$ & 9.8 & $18 \%$ & 8.7 & $15 \%$ & 15.7 & $20 \%$ \\
\hline EM & 23.5 & $21 \%$ & 16.6 & $13 \%$ & 9.6 & $17 \%$ & 13.1 & $11 \%$ & 18.7 & $15 \%$ \\
\hline \multicolumn{11}{|c|}{ Quarterly } \\
\hline & \multicolumn{2}{|c|}{ Aggregate flows } & \multicolumn{2}{|c|}{ Direct investment } & \multicolumn{2}{|c|}{$\begin{array}{c}\text { Portfolio } \\
\text { investment: Equity }\end{array}$} & \multicolumn{2}{|c|}{$\begin{array}{c}\text { Portfolio } \\
\text { investment: Debt }\end{array}$} & \multicolumn{2}{|c|}{ Other investment } \\
\hline & Corr. & Sign. & Corr. & Sign. & Corr. & Sign. & Corr. & Sign. & Corr. & Sign. \\
\hline Full sample & 14.3 & $32 \%$ & 4.2 & $12 \%$ & 5.4 & $19 \%$ & 6.5 & $18 \%$ & 9.3 & $20 \%$ \\
\hline$A E$ & 13.8 & $29 \%$ & 2.1 & $12 \%$ & 6.3 & $21 \%$ & 7.0 & $24 \%$ & 7.7 & $22 \%$ \\
\hline EM & 15.9 & $38 \%$ & 5.2 & $12 \%$ & 4.8 & $20 \%$ & 7.1 & $17 \%$ & 11.6 & $24 \%$ \\
\hline
\end{tabular}

*Scaled by 100 .

${ }^{* *}$ Corr. - correlation coefficient, Sign. - percentage of correlation coefficients that are significant; AE - advanced economies, EM - emerging markets.

Given that some variables are nonstationary, the paper uses first differences to calculate both correlations and factors. Bai and $\mathrm{Ng}$ (2008) show that factors and loadings are consistently estimated in first differences without prior knowledge of whether factors or idiosyncratic terms are $I(0)$ or $I(1)$. The factor is then obtained by cumulation. In addition, factors are generally estimated consistently using PCA with $N \rightarrow \infty$ under different misspecifications, including inappropriate specification of temporal evolution of the factors and time-varying factor loadings (Banerjee et al., 2008).

Although Bai and $\mathrm{Ng}$ (2002) information criteria suggest as much as 19 factors for the case of annual data and only one factor for quarterly, to conform with the general logic of experiment (global factor, annual vs. quarterly) a single factor with largest eigenvalue is used. It is common in the literature to associate the global cycle with the first factor, which, by construction, explains the largest portion of the overall variation in the data. At the same time, the $2^{\text {nd }}, 3^{\text {rd }}$ etc. factors, representing other forces - regional influences, commodity prices (as in Davis et al., 2019) - may also appear important from economic point of view. Bringing to the attention these forces is a relevant avenue for future research. ${ }^{5}$
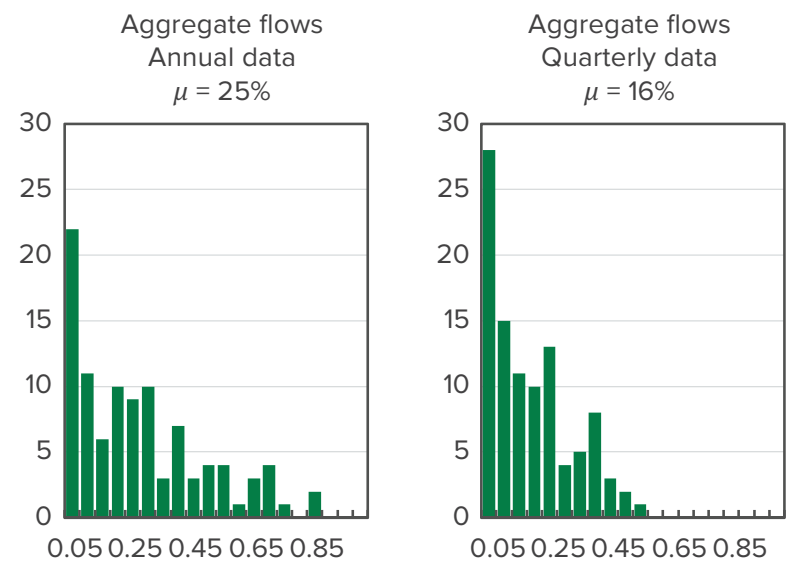

Figure 7 in the Appendix shows the extracted global factors from four panels of capital flows. Although annual and quarterly factors are generally comparable, except for magnitude, before the global financial crisis they show quite synchronous movement, while later local maxima and minima somewhat differ. For instance, the deepest point of the trough in disaggregated flows, caused by financial crisis, appears in 2008 in annual data but in 2009 in quarterly.

As data move from the most to the least aggregated state, the global factor tends to explain less and less volatility in capital flows. Although it might be reasonable to expect some proportional decline in the share of variance explained across all countries as one moves from annual to quarterly data, it is not supported by data. The interquartile range of ratio of annual to quarterly measure is wide, from 1.8 to 20.3 . Moreover, for $29 \%$ to $35 \%$ of flows the portion of volatility explained actually increase, on average, by 3.75 p.p. to 18.22 p.p. in disaggregated and aggregated data, respectively. The ranking of countries also changes: at different frequencies, top 10 flows in aggregated data are completely different, while in disaggregated data only two flows repeat. Hence, estimates of the significance of the global cycle, as it is commonly referred to, has some discrepancies of both quantitative and qualitative nature.
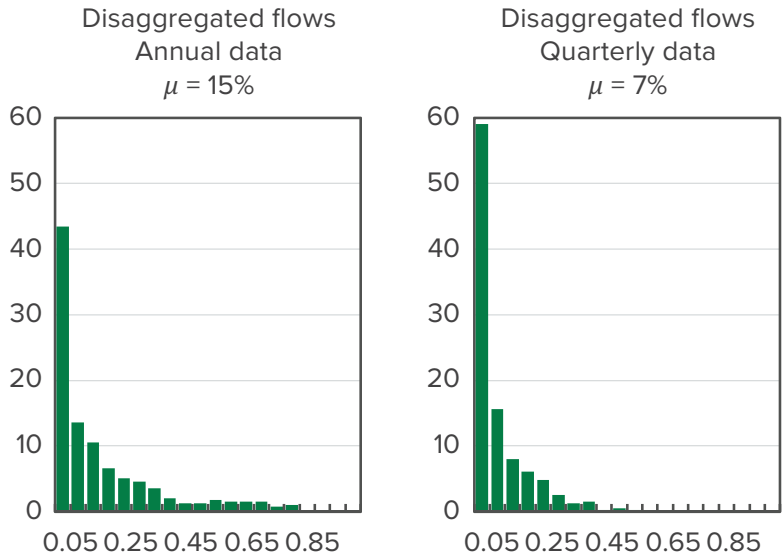

Figure 3. Cross-Country Differences in the Share of Variance Explained by Global Factor*, \% ${ }^{*} \mu$ indicates average. 
A decline in the share of variance explained matches the tendency in correlations, where less aggregated data had lower average pairwise correlation. Since loadings can be effectively interpreted as correlations between capital flows and the factor under the normalization $\Sigma_{f}=I$, the result is natural. To illustrate the point, Figure 8 in the Appendix shows a strong linear relationship between the number of significant pairwise correlations for a specific flow and the share of variance explained.

Thus, estimates of co-movement in capital flows vary, depending on data frequency and level of aggregation. The literature on temporal and cross-sectional aggregation confirms that these transformations can influence estimation results and model properties, such as dynamic patterns and Granger causality (Silvestrini and Veredas, 2008). Although to my knowledge, research on the topic in the context of factor models is limited, it is still possible to make inferences about potential issues, associated with aggregation, from the existing papers.

Granger (1987) shows that common factors are key to determine the dynamics of aggregates, though they might explain little at the micro level. Turning to capital flows, it is worth noting that - at least in the quarterly sample, where the time-series dimension $T$ is large - factors from crosssectionally aggregated and disaggregated flows exhibit quite similar behavior. At the same time, on average, the share of variance explained by the global factor is twice lower in the latter case, as Figure 3 demonstrates. Following Granger (1987), it is reasonable to conclude that the global cycle, having limited influence on specific FDI or portfolio flows at the micro level, should not be discarded entirely, as it can still play some role in macro level models.

Temporal aggregation smooths out high-frequency fluctuations and seasonal patterns in the data. However, Rossana and Seater (1995) argue that it systematically changes the time-series properties of the data. In particular, annual aggregates do not exhibit variation at business cycle frequencies (over 1 year), which is evident in monthly and quarterly data, and therefore, entail a significant loss of information about the actual data-generating process. In the PCA, which takes into account only contemporaneous observations, the cyclical pattern is still present, as shown in Figure 7 in the Appendix. How it compares to the cycle in the quarterly data is further explored in section 5 .

The observed quantitative importance of the global cycle as measured by the share of variance explained can be distorted not only by aggregation, but also by random events. Although being an extremely useful method to extract a global component, factor analysis per se does not guarantee that this component is a pure "cycle". In business cycle literature, a variable of interest $y_{t}$ is typically decomposed into trend and cycle as follows

$$
y_{t}=g_{t}+c_{t}+\varepsilon_{t}
$$

where $\varepsilon_{t}$ is a residual. After data is standardized as required by the PCA, both flows and the first factor are likely to be represented by a $c_{t}+\varepsilon_{t}$ rather than $c_{t}$ itself. Hence, at least one component, $\varepsilon_{t}$, might distort correlations (loadings) as a measure of synchronization between the global factor and capital flows. McDermott and Scott (2000) illustrate this case with an artificial example: two series were in the same phase of the cycle $50 \%$ of the time, and initially their correlation was small (0.12) and insignificant. The authors added a jump in both series at the same point in time, and the correlation grew to 0.6 while the phases of the cycles were left untouched. If, instead, the two series are correlated, and the jump is added to only one of them, the correlation is likely to fall while the correspondence in cycles - to be maintained. The next example from McDermott and Scott (2000) refers to the actual GDP data in the U.S. and Germany from the same paper. While the business cycle in both countries was largely synchronized, correlation turned out to be close to zero.

Accordingly, a deeper understanding of cyclical properties is required to judge to what extent the share of variance explained reflects the synchronization between the global cycle and capital flows.

\section{CONCORDANCE IN CAPITAL FLOWS}

One of the oldest strands of literature on cycles defines a cyclical component in an individual series by the existence of consecutive alternating turning points - peaks and troughs with periods in between being expansions and contractions. In this vein, two cycles are said to be synchronized if their corresponding turning points are so close to each other so that they share the same phase most of the time. The degree of synchronization is measured by the concordance index (Harding and Pagan, 2002), which is calculated as

$$
I=\frac{1}{T}\left(\sum_{t=1}^{T} S_{i, t} S_{j, t}+\sum_{t=1}^{T}\left(1-S_{i, t}\right)\left(1-S_{j, t}\right)\right),
$$

where $S_{i, t}$ indicates the state of capital flow $x_{i, t} ; S_{i, t}=1$ stands for expansion, and $S_{i, t}=0-$ for contraction. As inputs to the concordance index are binary, the results are not prone to changes in magnitudes either in specific periods or from cycle to cycle. Perfect positive synchronization occurs when $E(I)=1$, and perfect negative - if $E(I)=0$.

To construct binary indicators for each capital flow and estimated global factor, one needs to determine turning points in the series. In this paper, this task is accomplished, using the three-step procedure, outlined by Harding and Pagan (2002). First, a potential set of turning points is defined using rules for finding local minima and maxima, e.g. local maxima in series $x$ satisfies simultaneously the following conditions:

$$
\Delta_{2} x_{t}>0, \Delta x_{t}>0, \Delta x_{t+1}<0, \Delta_{2} x_{t+2}<0
$$

Second, one should ensure that peaks and troughs alternate. Third, additional rules apply to the resulting set, which specify minimum phase (contraction or expansion) and cycle duration. Harding and Pagan (2002) propose minimum phase duration of two quarters and minimum cycle duration of five quarters when applying the turning point detection algorithm to the business cycle. These values are typically used, but are not carved in stone, and in the same paper, the authors reduce the minimum cycle to four quarters for the UK, as an important recession episode is otherwise missing.

Thus, I generally follow the methodology by Harding and Pagan (2002) but somewhat adjust censoring rules on minimum phase and cycle duration. Borio (2019) states 
that the global cycle occurs at traditional business cycle frequencies, commonly referred to as two to eight years. Forbes and Warnock (2012), who study surges, stops, flights, and retrenchments in gross capital flows with a different methodology, find that on average each episode lasts about 3 to 5 quarters. Hence, the minimum phase is set to three quarters while the minimum cycle - to eight quarters. Since the turning points analysis does not require the underlying series to be stationary, a simple four-quarter moving average is used.

The cyclical properties of capital flows are outlined in Table 6. On average, expansion phases last somewhat longer than contractions, 9 and 7 quarters, respectively; the full cycle is thus about four years (or 16 quarters). Compared to inflows, outflows tend to be rather more stable, with the longest expansions recorded for EM countries in portfolio equity. This result, however, is likely to be distorted by the fact that in relation to GDP, portfolio equity flows are typically close to zero.

Coming back to the issue of temporal aggregation, turning point analysis highlights how differently one can define expansionary and contractionary years with annual and quarterly factors. For instance, the peak of the quarterly cycle occurs in Q2 2011 and only the two last quarters can be marked as contractionary while in the annual data, the peak is observed a year earlier, and 2011 is already believed to be contractionary. The reverse can be said about 2012 . Moreover, the quarterly factor tends to display less abrupt changes, especially during contractions, as shown in the lower panel of Figure 7 in the Appendix. Therefore, the loss of information entailed by temporal aggregation can result in an improper contemporaneous analysis and model specification (if used as an input).

Having defined the turning points for individual capital flows, the paper also extracts a common cycle using the non-parametric method as defined in Harding and Pagan (2006). This entails the determination of clusters of turning points in individual capital flows; for a detailed procedure, one is referred to the original paper. Figure 4 shows global cycles estimated from aggregate capital flows, from risky asset prices (Miranda-Agrippino and Rey, 2020; Habib and Venditti, 2019), and contraction phases obtained by the non-parametric algorithm. ${ }^{6}$ All cyclical representations generally co-move, and their turning points are clustered around the same dates. The only notable discrepancy occurs in 2002-03 with a trough in capital flows occurring earlier than in asset prices. Hence, all series are likely to represent the same underlying phenomena, named the "Global Financial Cycle".

Since in the present paper, the purpose of concordance analysis is to construct an alternative co-movement measure, with which the share of variance explained can be compared, global factors extracted by the PCA are used as benchmarks, with which country flows are assumed to be synchronous. Figure 10 in the Appendix shows the distributions of the degree of concordance between global factors and individual flows. On average, capital flows, reported by 50 countries, spend about $60-65 \%$ of the time in the same phase as the global cycle. Does this hint at a significant (in econometric terms) synchronization? As noted in Harding and Pagan (2006), $E(I)=0.5$ points to strong non-synchronization between two series only if both spend about $50 \%$ of time equally in expansion and contraction phases. Therefore, to test whether the two have a significant synchronization, it is required to mean correct it, i.e. estimate correlation $\rho_{S}$ between the binary series $S_{i}$ and $S_{j}$.

Harding and Pagan (2006) specify the following regression, from which $\rho_{S}$ can be inferred:

$$
\frac{S_{j, t}}{\hat{\sigma}_{S_{i}} \hat{\sigma}_{S_{j}}}=a_{1}+\rho_{S} \cdot \frac{S_{i, t}}{\hat{\sigma}_{S_{i}} \hat{\sigma}_{S_{j}}}+u_{t}
$$

where $\hat{\sigma}_{S i}$ is a standard deviation of $S_{i}, a_{1}$ is some constant, and $u_{t}$ is an error term. Since $S_{i}$ and $S_{j}$ typically exhibits serial correlation, neither is safe to assume $u_{t}$ is i.i.d., so the equation is estimated by the generalized method of moments.

Figures 5 and 6 plots the concordance index with the global factor versus the portion of volatility in capital flow explained by this factor. If the latter properly reflects the degree of synchronization with the cycle, one would expect a high and significant concordance index to correspond to

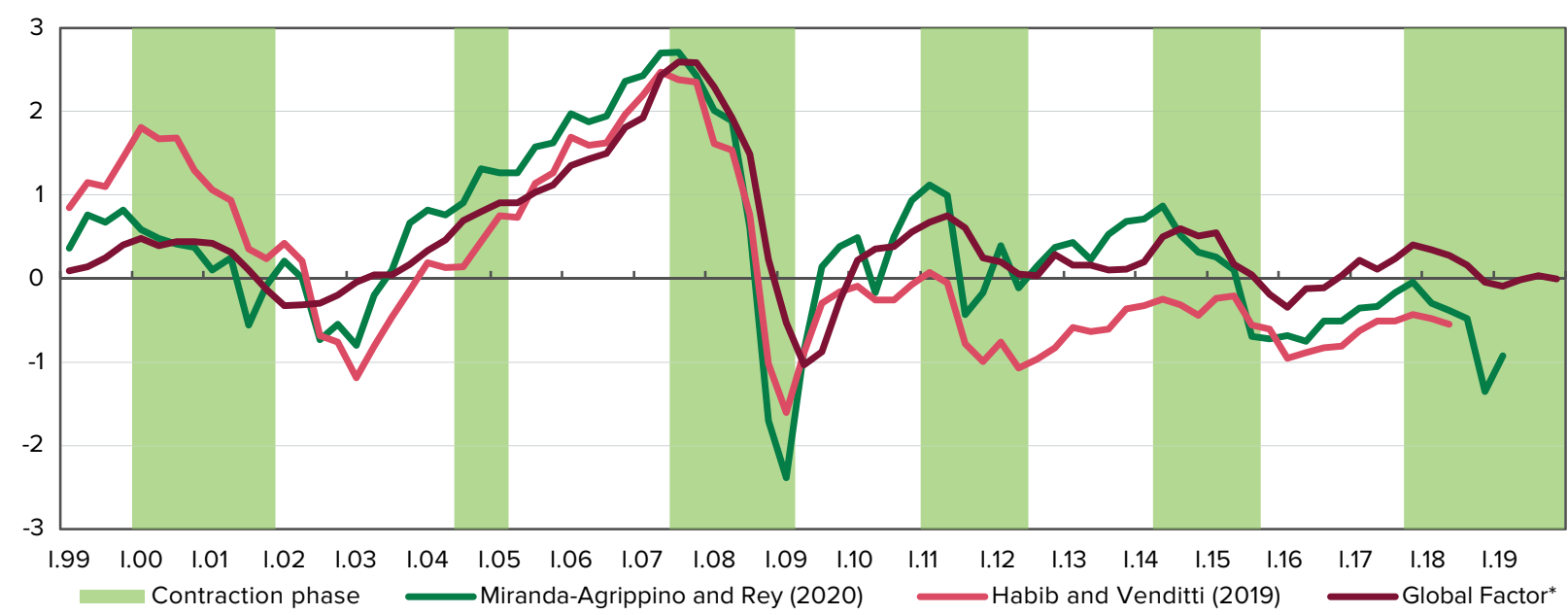

Figure 4. Estimates of the Global Financial Cycle

*The global factor from aggregated flows; scaled by 0.25 for visibility.

Source: own elaboration, personal web page of Miranda-Agrippino, and personal web page of Venditti. 
a high share of variance explained. The evidence generally supports this statement, although it is not one-to-one correspondence, and the high and significant degree of synchronization can occur even if the factor explains only a small part of the variance.

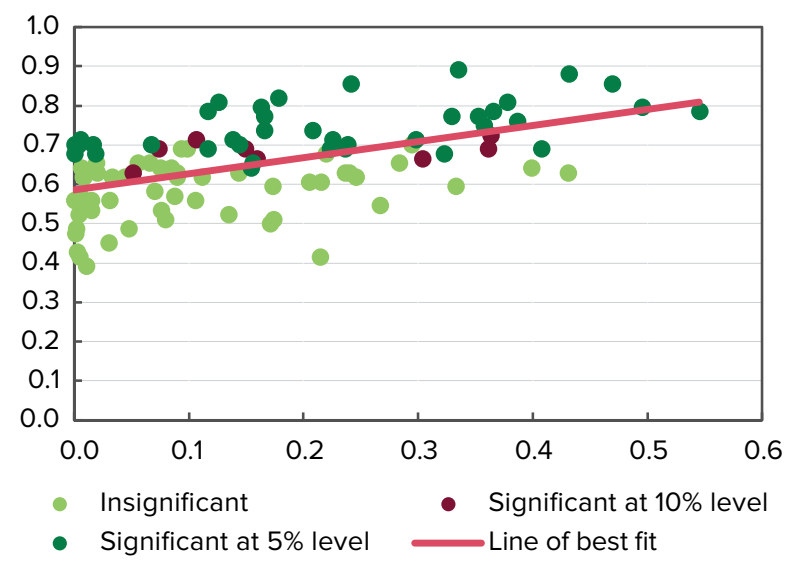

Figure 5. Share of Variance Explained and Concordance Index in Aggregate Capital Flows

Share of flows significant* at $5 \%$ is $38 \%$

Share of flows significant* at $10 \%$ is $46 \%$

*Significance refers to the concordance index. Dots represent capital flows, e.g. outflows from the U.S. or inflows into Ukraine.

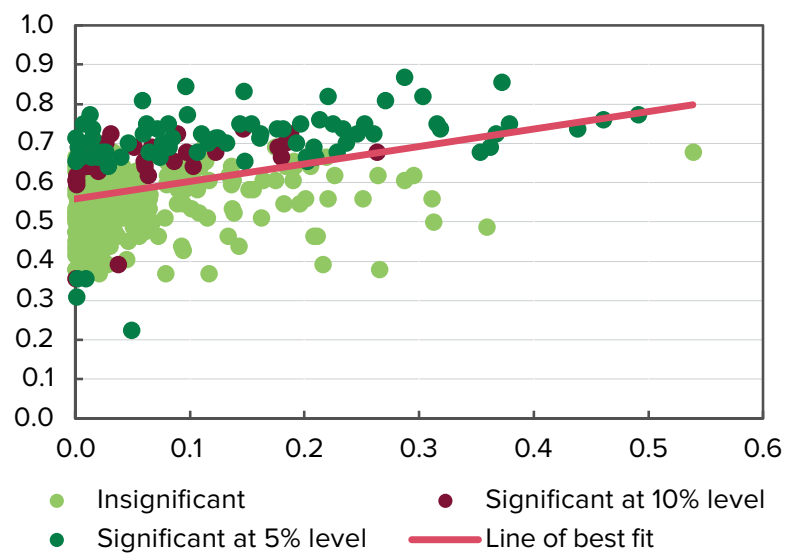

Figure 6. Share of Variance Explained and Concordance Index in Capital Flows (split by types)

Share of flows significant* at $5 \%$ is $19 \%$

Share of flows significant* at $10 \%$ is $28 \%$

*Significance refers to the concordance index. Dots represent capital flows, e.g. outflows from the U.S. or inflows into Ukraine.

Figure 11 in the Appendix illustrates what this implies in practice for the case of three aggregate flows, taken from the different parts of a spectrum. Capital outflows from Korea, characterized by both high share of variance explained and concordance, exhibit dynamics quite similar to that of the global factor. ${ }^{7}$ On the contrary, inflows to Hungary are more volatile and change their magnitude from phase to phase. Additionally, a spike in 2016, not matched by an equivalent event in the global factor, was likely to play a role in lowering the correlation between the series. At the same time, expansion and contraction periods, by and large, occur simultaneously. As a result, a very small part of the variance is explained by the global variable but the degree of synchronization is high. Inflows to Peru provide an example of a flow that is not well aligned with the cycle.

Generally, about half of aggregate flows in the sample have a statistically significant degree of concordance, both in advanced and emerging economies (Table 7). In the $A E$ group, out of 17 countries, six have inflows and outflows co-moving with the global cycle (including the U.S.), and in another five - one type of flow. Among EM, new Eurozone members and countries included in MSCI EM typically have at least one flow with significant concordance index. This might suggest the presence of a link between the level of financial development or the country's openness and adherence to the global cycle, a topic to be covered in further research.

It is interesting to note that, in line with the previous research, net flows exhibit limited concordance with the global factor - only 7 out of 50 countries have the index significant. ${ }^{8}$ In Turkey and Argentina, inflows dominate, and net flows co-move with the global cycle because inflows do so. In the U.S., Latvia, and Slovakia, inflows and outflows generally offset each other, but the resulting net flows are positively synchronized with the factor, while in Chile - negatively synchronized. In general, net flows are either rather stable with soft cycles or exhibit more short cycles, and spend less time in the same phase as the global factor - about $55 \%$ of the time.

As for the disaggregated data (Table 8), there are several things to mention here. First, 59\% of advanced economy and $23 \%$ of emerging market portfolio equity flows have a significant concordance. This is quite an intuitive result, given the high degree of similarity between the global factors estimated from capital flows and risky asset prices. Second, other investment flows are also synchronized with the global cycle: $38 \%$ and $23 \%$ of $A E$ and EM flows, respectively. Direct investment flows are the least numerous category, but for seven EM countries, inflows are significantly procyclical, while for Slovakia - significantly countercyclical.

The U.S. is an absolute leader in terms of the number of flows, co-moving with the global cycle. Yet there is limited room for the egg vs. chicken debate. Miranda-Agrippino and Rey (2020) show that U.S. monetary policy is an important driver of the global financial cycle, as measured by a global factor. Other advanced economies have on average about three synchronized flows, France and Germany - four. Countries from the EM group usually have two types of flows with significant concordance index, while nine countries, including Mexico and Ukraine - none.

As a final note, it is necessary to admit that the detection of turning points was done automatically via an algorithm without any judgmental input. Some disagreements between the results of an algorithm and one's perception may arise at the visual inspection since the data is volatile. If used for policymaking, the turning points and concordance index should be checked on a case-by-case basis.

\footnotetext{
${ }^{7}$ Remember, the factor model is estimated in first differences. Except for the "trending part" (constant in growth rate) after 2009, the dynamics are similar, as well as scale.

${ }^{8}$ See, for example, Rey (2015).
} 


\section{CONCLUSIONS}

The global financial cycle, as virtually any unobservable variable, has no unambiguous estimate. The literature on the topic is centered on the estimation of factor models, which offer useful insight into how the global cycle might look like. It is also quite common to infer its quantitative importance for individual capital flows from the share of variance explained by the factor. In the case of volatile data, however, it might appear misleading.

The paper studies four instances of factor analysis applied to datasets, differing in the level of temporal and cross-sectional aggregation. Although the cyclical patterns of factors extracted from annual and quarterly data are roughly similar, on average, the former points to its higher quantitative importance for capital flows than the latter. The ordering of flows from the most to the least synchronous (or the other way round) is also unstable. Still, if one continues to see the matter through the prism of the factor model, the share of variance explained by the factor is probably the only ready-made estimate of its significance.

Notwithstanding the fact that the setup of the factor model should be chosen, depending on the purpose of the exercise, it is reasonable to suggest the use of quarterly capital flows for estimation purposes. ${ }^{9}$ First, data at this frequency provide a consistent estimate of the factor for cross-sectionally aggregated and disaggregated data, or as $N \rightarrow \infty$. Second, according to the literature, it is likely to reflect cyclical properties and the data-generating process better if used in macro modeling. Third, transforming data in the temporal dimension occasionally changes the interpretation of a particular year from expansionary to contractionary, and vice versa.

Turning back to the share of variance explained, there is the additional (and more important) rationale behind questioning it as a measure of synchronization: the factor model does not guarantee that the extracted component is a pure "cycle". Thus, this paper changes the vantage point, moving from factor models to the traditional approach used in the business cycle and domestic financial cycle analysis. It involves the determination of turning points and expansion-contraction phases in capital flows. The degree of synchronization with the global factor is then measured by the concordance index.

The two alternatives are interrelated: in general, a high share of variance explained corresponds to a high and significant concordance index. However, this is not always the case: as correlations might be distorted by single events in series or varying magnitudes from phase to phase, so does the share of variance explained. At the same time, the co-movement of cyclical components in capital flows might be preserved.
As of now, the paper does not either compare the unobservable global cycle with cycles in potential observable counterparts, e.g. VIX, nor does it draw inferences on its source. It also omits the question of what country-specific characteristics - like capital account openness, flexible/fixed exchange rates, and level of financial developments - make country's flows more susceptible to the global cycle. Testing dilemma vs. trilemma theories, depending on the degree of co-movement between the global cycle and capital flows, is a promising direction for future research.

From a policymaking perspective, it is safe to assume that inflows and outflows scoring high on both measures of synchronization are dancing to the tune of the global cycle or are transmitting this cycle to the rest of the world (e.g., the U.S., although from the present analysis, it is impossible to distinguish between the two). In these instances, developments in individual flows - phases of the cycle and quarter-to-quarter changes - are coinciding with those in the global factor.

The number of such instances is limited, however. Although a case-by-case investigation is warranted, overall there is little evidence of an extensive and stable impact of the global financial cycle on capital flows. The use of the concordance index helps to broaden the subset of series to be watched more closely - now some of those with a low share of variance explained can be treated as synchronized with the global cycle. Still, in EM countries, on average, only two out of eight types of flows have a significant concordance index.

Although this paper does not provide any robust evidence on what level of co-movement hampers the ability of policymakers to conduct independent monetary policy, when the capital account is open, the results cast a shadow on a basic precondition for trilemma turning into dilemma. While additional research on the topic is warranted, it is still might be more relevant for policymakers to concentrate on fundamentals. This generally echoes a summary from pushpull literature by Koepke (2015), according to which the importance of cyclical factors may have been overstated at the expense of longer-term structural trends.

\footnotetext{
${ }^{9}$ Whenever only annual flows are available, the factor model should probably encompass more than 20 years of data to yield consistent results. This proposal, however, requires additional analysis.
} 


\section{REFERENCES}

Bai, J. Ng, S. (2002). Determining the number of factors in approximate factor models. Econometrica, 70 (1), 191-221. https://doi.org/10.1111/1468-0262.00273

Bai, J., Ng, S. (2008). Large dimensional factor analysis. Foundations and Trends $^{\circledR}$ in Econometrics, 3(2), 89-163. https://doi.org/10.1561/0800000002

Banerjee, A., Marcellino, M., Masten, I. (2008). Forecasting macroeconomic variables using diffusion indexes in short samples with structural change. CEPR Discussion Paper, 6706. Retrieved from https://cepr.org/active/publications/ discussion_papers/dp.php?dpno=6706

Barigozzi, M. (2018). Dynamic Factor Models. Lecture notes. Retrieved from http://www.barigozzi.eu/MB_DF_ lecture_notes.pdf

Barrot, L., Serven, L. (2018). Gross capital flows, common factors, and the global financial cycle. Policy Research Working Paper, 8354. http://hdl.handle.net/10986/29414

Borio, Claudio (2019). A tale of two financial cycles: domestic and global. Lecture at the University of Zürich Retrieved from https://www.bis.org/speeches/sp191119a.pdf

Boivin, J., Ng S. (2006). Are more data always better for factor analysis? Journal of Econometrics, 132(1), 169-194. https://doi.org/10.1016/j.jeconom.2005.01.027

Broner, F., Didier, T., Erce, A., Schmuker S. (2013). Gross capital flows: dynamics and crises. Journal of Monetary Economics, 60(1), 113-133. https://doi.org/10.1016/j. jmoneco.2012.12.004

Calvo, G. A., Leiderman, L., Reinhart, C. M. (1993). Capital inflows and real exchange rate appreciation in Latin America: the role of external factors. IMF Staff Papers, 40(1), 108-151. Retrieved from https://www.jstor.org/stable/3867379

Calvo, G. A., Leiderman, L., Reinhart, C. M. (1996). Inflows of capital to developing countries in the 1990s. Journal of Economic Perspectives, 10(2), 123-139. https://doi. org/10.1257/jep.10.2.123

Cerutti, E., Claessens, S., Rose A. K. (2017). How important is the global financial cycle? Evidence from capital flows. NBER Working Paper, 23699. Cambridge: National Bureau of Economic Research. https://doi.org/10.3386/w23699

Claessens, S., Kose, M. A., Terrones, M. E. (2011) Financial cycles: What? How? When? NBER International Seminar on Macroeconomics, 7(1), 303-344. https://doi. org/10.1086/658308

Claessens, S., Kose, M. A., Terrones, M. E. (2012). How do business and financial cycles interact? Journal of International Economics, 87(1), 178-190. https://doi. org/10.1016/j.jinteco.2011.11.008

Davis, J. S., Valente, G., van Wincoop, E. (2019). Global drivers of gross and net capital flows. Globalization Institute Working Paper, 357. https://doi.org/10.24149/gwp357
Drehmann, M., Borio, C., Tsatsaronis, K. (2012). Characterising the financial cycle: Don't lose sight of the medium term! BIS Working Paper, 380. Retrieved from http://www.bis.org/publ/work380.pdf

Fernandez-Arias, E. (1996). The new wave of private capital inflows: Push or pull? Journal of Development Economics, 48(2), 389-418. https://doi.org/10.1016/03043878(95)00041-0

Forbes, K. J., Warnock, F. E. (2012). Capital flow waves: Surges, stops, flight, and retrenchment. Journal of International Economics, 88(2), 235-251. https://doi. org/10.1016/j.jinteco.2012.03.006

Ghosh, A. R., Qureshi, M. S., Kim, J. I., Zalduendo, J. (2014). Surges. Journal of International Economics, 92(2), 266-285. https://doi.org/10.1016/j.jinteco.2013.12.007

Granger, C. W. J. (1987). Implications of aggregation with common factors. Econometric Theory, 3(2), 208-222. Retrieved from https://www.jstor.org/stable/3532462

Habib, M. M., Venditti, F. (2019).The global capital flows cycle: structural drivers and transmission channels. ECB Working Paper Series, 2280. Retrieved from https://www. ecb.europa.eu/pub/pdf/scpwps/ecb.wp2280 2e76974901. en.pdf

Harding, D., Pagan, A. (2002). Dissecting the cycle: a methodological investigation. Journal of Monetary Economics, 49(2), 365-381. https://doi.org/10.1016/S03043932(01)00108-8

Harding, D., Pagan, A. (2006). Synchronization of cycles. Journal of Econometrics, 132(1), 59-79. https://doi. org/10.1016/j.jeconom.2005.01.023

IMF (2012). The Liberalization and Management of Capital Flows: An Institutional View. Retrieved from https://www.imf.org/external/np/pp/eng/2012/111412.pdf

Koepke, R. (2015). What drives capital flows to emerging markets? A Survey of the Empirical Literature. MPRA Paper, 75887. Retrieved from https://mpra.ub.uni-muenchen. de/75887/

Lane, P. R., Milesi-Ferretti, G. M. (2017). International financial integration in the aftermath of the global financial crisis. IMF Working Paper, 17/115. Retrieved from https:// www.imf.org/en/Publications/WP/Issues/2017/05/10/ International-Financial-Integration-in-the-Aftermath-of-theGlobal-Financial-Crisis-44906

Lutkepohl, H. (2014). Structural vector autoregressive analysis in a data rich environment. DIW Discussion Paper, 1351. Retrieved from https://www.diw.de/documents/ publikationen/73/diw_01.c.434718.de/dp1351.pdf

McDermott, C. J., Scott, A. (2000). Concordance in business cycles. IMF Working Paper, 00/37. Retrieved from https://www.imf.org/en/Publications/WP/Issues/2016/12/30/ Concordance-in-Business-Cycles-3517 
Miranda-Agrippino, S., Rey, H. (2020). U.S. monetary policy and the global financial cycle. The Review of Economic Studies, 87(6), 2754-2776. https://doi.org/10.1093/restud/ rdaa019

Reinhart, C. M., Reinhart, V., Trebesch, C. (2016). Global cycles: Capital flows, commodities, and sovereign defaults, 1815-2015. American Economic Review, 106(5), 574-580. http://doi.org/10.1257/aer.p20161014

Rey, H. (2015). Dilemma not trilemma: The global financial cycle and monetary policy independence. NBER Working Paper, 21162. https://doi.org/10.3386/w21162
Rossana, R. J., Seater, J. J. (1995). Temporal aggregation and economic time series. Journal of Business \& Economic Statistics, 13(4), 441-451. Retrieved from https://doi. org/10.2307/1392389

Schuler, Y. S., Hiebert, P. P., Peltonen, T. A. (2015). Characterising the financial cycle: A multivariate and timevarying approach. ECB Working Paper, 1846. Retrieved from https://www.ecb.europa.eu/pub/pdf/scpwps/ecbwp1846. en.pdf

Silvestrini, A., Veredas, D. (2008). Temporal aggregation of univariate and multivariate time series models: A survey. Bank of Italy Working Paper, 685. Retrieved from https://www.bancaditalia.it/pubblicazioni/ temi-discussione/2008/2008-0685/en_tema_685.pdf 
APPENDIX A. TABLES

Table 2. Country Classification

\begin{tabular}{|c|c|c|}
\hline Advanced economies & Emerging markets & Financial centers ${ }^{10}$ \\
\hline Australia & Argentina & Belgium \\
\hline Austria & Brazil & Cyprus \\
\hline Canada & Bulgaria & Hong Kong S.A.R. of China \\
\hline Denmark & Chile & Ireland \\
\hline Finland & China & Luxembourg \\
\hline France & Colombia & Macao S.A.R. of China \\
\hline Germany & Costa Rica & Malta \\
\hline Greece & Croatia & Mauritius \\
\hline Israel & Czech Republic & Netherlands \\
\hline Italy & Estonia & Singapore \\
\hline Japan & Georgia & Switzerland \\
\hline New Zealand & Hungary & United Kingdom \\
\hline Norway & Iceland & \\
\hline Portugal & India & \\
\hline Spain & Indonesia & \\
\hline Sweden & Kazakhstan & \\
\hline \multirow[t]{17}{*}{ United States } & Korea & \\
\hline & Latvia & \\
\hline & Lithuania & \\
\hline & Malaysia & \\
\hline & Mexico & \\
\hline & Peru & \\
\hline & Philippines & \\
\hline & Poland & \\
\hline & Romania & \\
\hline & Russia & \\
\hline & Slovakia & \\
\hline & Slovenia & \\
\hline & South Africa & \\
\hline & Sri Lanka & \\
\hline & Thailand & \\
\hline & Turkey & \\
\hline & Ukraine & \\
\hline
\end{tabular}


Table 3. Descriptive Statistics

\begin{tabular}{|c|c|c|c|c|c|c|c|}
\hline & \multicolumn{3}{|c|}{ Inflows } & \multicolumn{3}{|c|}{ Outflows } & \multirow{2}{*}{$\begin{array}{l}\text { Correlation } \\
\text { in-outflows }\end{array}$} \\
\hline & Mean & Median & St. dev. & Mean & Median & St. dev. & \\
\hline \multicolumn{8}{|c|}{ Annual data } \\
\hline \multicolumn{8}{|c|}{ Aggregate flows } \\
\hline Full sample & 7.54 & 6.28 & 4.91 & 4.33 & 4.36 & 3.55 & 0.68 \\
\hline$A E$ & 9.44 & 9.51 & 8.09 & 7.89 & 7.56 & 6.82 & 0.90 \\
\hline EM & 6.15 & 5.76 & 4.53 & 2.90 & 2.89 & 2.65 & 0.63 \\
\hline \multicolumn{8}{|c|}{ Disaggregated flows } \\
\hline DI & 3.13 & 2.79 & 1.78 & 1.12 & 1.04 & 1.22 & 0.59 \\
\hline $\mathrm{DI}-\mathrm{AE}$ & 2.49 & 2.08 & 1.95 & 3.28 & 2.36 & 1.94 & 0.61 \\
\hline $\mathrm{DI}-\mathrm{EM}$ & 3.33 & 3.12 & 1.61 & 0.90 & 0.83 & 0.88 & 0.51 \\
\hline PI D & 1.46 & 1.10 & 2.01 & 0.84 & 0.68 & 1.01 & 0.13 \\
\hline$P I D-A E$ & 3.32 & 3.19 & 3.52 & 2.26 & 2.13 & 2.35 & 0.38 \\
\hline PI D - EM & 1.05 & 0.80 & 1.68 & 0.40 & 0.35 & 0.72 & 0.04 \\
\hline PIE & 0.25 & 0.17 & 0.77 & 0.58 & 0.45 & 0.83 & 0.05 \\
\hline $\mathrm{PIE}-\mathrm{AE}$ & 0.70 & 0.70 & 1.28 & 1.40 & 1.38 & 1.27 & 0.22 \\
\hline $\mathrm{PI} E-\mathrm{EM}$ & 0.13 & 0.08 & 0.41 & 0.34 & 0.21 & 0.54 & 0.05 \\
\hline Ol & 2.03 & 1.28 & 3.23 & 1.24 & 1.35 & 2.31 & 0.39 \\
\hline $\mathrm{OI}-\mathrm{AE}$ & 2.13 & 2.01 & 5.06 & 1.75 & 1.64 & 4.04 & 0.66 \\
\hline OI - EM & 1.37 & 0.89 & 2.41 & 1.05 & 0.86 & 1.59 & 0.27 \\
\hline \multicolumn{8}{|c|}{ Quarterly data } \\
\hline \multicolumn{8}{|c|}{ Aggregate flows } \\
\hline Full sample & 7.66 & 6.38 & 7.90 & 4.17 & 4.26 & 6.05 & 0.62 \\
\hline$A E$ & 9.05 & 8.48 & 12.34 & 8.09 & 7.44 & 10.92 & 0.91 \\
\hline EM & 6.19 & 5.56 & 6.54 & 2.84 & 2.62 & 4.69 & 0.45 \\
\hline \multicolumn{8}{|c|}{ Disaggregated flows } \\
\hline DI & 3.11 & 2.93 & 2.68 & 1.13 & 0.87 & 1.77 & 0.41 \\
\hline $\mathrm{DI}-\mathrm{AE}$ & 2.53 & 2.11 & 3.83 & 3.32 & 2.81 & 3.47 & 0.49 \\
\hline $\mathrm{DI}$ - EM & 3.38 & 3.10 & 2.49 & 0.89 & 0.68 & 1.48 & 0.28 \\
\hline PI D & 1.47 & 0.95 & 3.65 & 0.84 & 0.69 & 1.77 & 0.11 \\
\hline PI D - AE & 3.35 & 2.91 & 6.58 & 2.27 & 1.67 & 3.58 & 0.28 \\
\hline PI D - EM & 1.06 & 0.36 & 2.72 & 0.40 & 0.32 & 1.36 & 0.06 \\
\hline PIE & 0.25 & 0.21 & 1.36 & 0.60 & 0.49 & 1.16 & 0.04 \\
\hline $\mathrm{PI} E-\mathrm{AE}$ & 0.71 & 0.65 & 2.33 & 1.49 & 1.35 & 2.06 & 0.10 \\
\hline PI E - EM & 0.14 & 0.06 & 0.76 & 0.33 & 0.17 & 0.77 & 0.04 \\
\hline OI & 1.96 & 1.38 & 4.99 & 1.26 & 1.09 & 4.60 & 0.35 \\
\hline $\mathrm{OI}-\mathrm{AE}$ & 2.25 & 1.82 & 9.30 & 1.83 & 1.77 & 8.72 & 0.65 \\
\hline OI - EM & 1.32 & 0.96 & 4.28 & 1.06 & 0.89 & 3.77 & 0.26 \\
\hline
\end{tabular}

*Values represent medians of means, medians, and standard deviations over individual countries.

${ }^{* *} \mathrm{AE}$ - advanced economies; EM - emerging markets; DI - direct investment; PI D - portfolio investment in debt; PI E - portfolio investment in equity; $\mathrm{Ol}$ - other investment. 
Table 4. Within-Year Variation in Quarterly Capital Flows

\begin{tabular}{l|c|c|c|c}
\hline & \multicolumn{2}{|c|}{ Inflows } & \multicolumn{2}{c}{ Outflows } \\
\hline & Raw data & Moving average & Raw data & Moving average \\
\hline Aggregate flows & 4.55 & 1.59 & 3.54 & 1.07 \\
Direct investment & 1.53 & 0.53 & 0.95 & 0.40 \\
Portfolio debt & 2.24 & 0.86 & 1.39 & 0.47 \\
Portfolio equity & 0.57 & 0.24 & 0.57 & 0.21 \\
\hline Other investment & 3.50 & 1.13 & 3.54 & 1.07 \\
\hline
\end{tabular}

*Values represent medians.

Table 5. Unweighted Aaverages of Bilateral Correlation Coefficients* of Capital Outflows and Percentages of Significant Correlations**

\begin{tabular}{|c|c|c|c|c|c|c|c|c|c|c|}
\hline \multicolumn{11}{|c|}{ Annual } \\
\hline & \multicolumn{2}{|c|}{ Aggregate flows } & \multicolumn{2}{|c|}{ Direct investment } & \multicolumn{2}{|c|}{$\begin{array}{c}\text { Portfolio } \\
\text { investment: Equity }\end{array}$} & \multicolumn{2}{|c|}{$\begin{array}{c}\text { Portfolio } \\
\text { investment: Debt }\end{array}$} & \multicolumn{2}{|c|}{ Other investment } \\
\hline & Corr. & Sign. & Corr. & Sign. & Corr. & Sign. & Corr. & Sign. & Corr. & Sign. \\
\hline Full sample & 15.0 & $18 \%$ & 8.9 & $11 \%$ & 19.8 & $23 \%$ & 6.6 & $12 \%$ & 8.4 & $15 \%$ \\
\hline $\mathrm{AE}$ & 22.5 & $21 \%$ & 11.5 & $12 \%$ & 21.8 & $36 \%$ & 11.4 & $15 \%$ & 17.0 & $27 \%$ \\
\hline EM & 11.2 & $16 \%$ & 8.1 & $12 \%$ & 21.3 & $24 \%$ & 4.1 & $13 \%$ & 5.3 & $14 \%$ \\
\hline \multicolumn{11}{|c|}{ Quarterly } \\
\hline & \multicolumn{2}{|c|}{ Aggregate flows } & \multicolumn{2}{|c|}{ Direct investment } & \multicolumn{2}{|c|}{$\begin{array}{c}\text { Portfolio } \\
\text { investment: Equity }\end{array}$} & \multicolumn{2}{|c|}{$\begin{array}{c}\text { Portfolio } \\
\text { investment: Debt }\end{array}$} & \multicolumn{2}{|c|}{ Other investment } \\
\hline & Corr. & Sign. & Corr. & Sign. & Corr. & Sign. & Corr. & Sign. & Corr. & Sign. \\
\hline Full sample & 8.1 & $21 \%$ & 3.2 & $14 \%$ & 10.2 & $27 \%$ & 4.0 & $15 \%$ & 4.4 & $16 \%$ \\
\hline $\mathrm{AE}$ & 13.1 & $27 \%$ & 3.2 & $16 \%$ & 14.1 & $49 \%$ & 6.9 & $16 \%$ & 9.6 & $24 \%$ \\
\hline EM & 5.8 & $19 \%$ & 3.4 & $17 \%$ & 9.1 & $23 \%$ & 2.5 & $13 \%$ & 2.8 & $13 \%$ \\
\hline
\end{tabular}

*Scaled by 100 .

${ }^{* *}$ Corr. - correlation coefficient, Sign. - percentage of correlation coefficients that are significant; AE - advanced economies, EM - emerging markets.

Table 6. Cyclical Properties of Capital Flows*

\begin{tabular}{|c|c|c|c|c|c|c|c|c|c|c|}
\hline & \multicolumn{2}{|c|}{ Aggregate flows } & \multicolumn{2}{|c|}{ Direct investment } & \multicolumn{2}{|c|}{$\begin{array}{c}\text { Portfolio } \\
\text { investment: Equity }\end{array}$} & \multicolumn{2}{|c|}{$\begin{array}{c}\text { Portfolio } \\
\text { investment: Debt }\end{array}$} & \multicolumn{2}{|c|}{ Other investmen } \\
\hline & In. & Out. & In. & Out. & In. & Out. & In. & Out. & In. & Out. \\
\hline Expansion & 8.7 & 8.5 & 7.6 & 8.7 & 7.9 & 9.6 & 8.4 & 8.9 & 9.2 & 8.2 \\
\hline $\mathrm{AE}$ & 7.8 & 7.9 & 7.5 & 8.6 & 7.1 & 8.8 & 8.7 & 7.7 & 8.9 & 7.9 \\
\hline EM & 9.2 & 8.8 & 7.7 & 8.8 & 8.4 & 10.1 & 8.1 & 9.5 & 9.3 & 8.4 \\
\hline Contraction & 6.9 & 6.7 & 7.8 & 7.4 & 8.1 & 7.1 & 6.7 & 7.6 & 6.8 & 6.8 \\
\hline $\mathrm{AE}$ & 6.4 & 6.5 & 7.9 & 8.2 & 6.9 & 7.1 & 7.2 & 7.0 & 6.6 & 7.0 \\
\hline EM & 7.1 & 6.8 & 7.8 & 7.1 & 8.8 & 7.0 & 6.4 & 7.9 & 7.0 & 6.7 \\
\hline
\end{tabular}

${ }^{*} \mathrm{AE}$ - expansion/contraction of capital flows to/from advanced economies; EM - expansion/contraction of capital flows to/from emerging markets; In. - inflows, Out. - outflows. 
Table 7. Capital Flows with a Significant Degree of Concordance*

\begin{tabular}{|c|c|c|c|c|c|}
\hline \multicolumn{6}{|c|}{ Aggregate flows } \\
\hline & $\begin{array}{c}\text { \% of variance } \\
\text { explained }\end{array}$ & $\begin{array}{c}\text { Concordance } \\
\text { index }\end{array}$ & & $\begin{array}{c}\% \text { of variance } \\
\text { explained }\end{array}$ & $\begin{array}{c}\text { Concordance } \\
\text { index }\end{array}$ \\
\hline MY: outflow & $33 \%$ & 0.89 & TR: inflow & $22 \%$ & 0.71 \\
\hline US: outflow & $43 \%$ & 0.88 & BR: outflow & $11 \%$ & 0.71 \\
\hline US: inflow & $47 \%$ & 0.86 & AT: inflow & $14 \%$ & 0.70 \\
\hline IL: outflow & $24 \%$ & 0.86 & DK: inflow & $7 \%$ & 0.70 \\
\hline SE: outflow & $18 \%$ & 0.82 & HU: inflow & $0 \%$ & 0.70 \\
\hline AU: inflow & $13 \%$ & 0.81 & BG: outflow & $2 \%$ & 0.70 \\
\hline SI: outflow & $38 \%$ & 0.81 & CL: outflow & $24 \%$ & 0.70 \\
\hline IN: inflow & $50 \%$ & 0.80 & HR: outflow & $0 \%$ & 0.70 \\
\hline LV: outflow & $16 \%$ & 0.80 & KR: inflow & $41 \%$ & 0.69 \\
\hline IL: inflow & $12 \%$ & 0.79 & IT: outflow & $22 \%$ & 0.69 \\
\hline MY: inflow & $37 \%$ & 0.79 & CN: outflow & $12 \%$ & 0.69 \\
\hline KR: outflow & $55 \%$ & 0.79 & IS: outflow & $24 \%$ & 0.69 \\
\hline FR: inflow & $33 \%$ & 0.77 & PT: inflow & $7 \%$ & 0.69 \\
\hline SI: inflow & $35 \%$ & 0.77 & BR: inflow & $36 \%$ & 0.69 \\
\hline TH: outflow & $17 \%$ & 0.77 & GE: inflow & $15 \%$ & 0.69 \\
\hline LV: inflow & $39 \%$ & 0.76 & Fl: inflow & $2 \%$ & 0.68 \\
\hline $\mathrm{CN}$ : inflow & $36 \%$ & 0.75 & CO: outflow & $0 \%$ & 0.68 \\
\hline SE: inflow & $17 \%$ & 0.74 & PL: outflow & $32 \%$ & 0.68 \\
\hline AR: inflow & $21 \%$ & 0.74 & NZ: inflow & $30 \%$ & 0.67 \\
\hline FR: outflow & $36 \%$ & 0.73 & AT: outflow & $16 \%$ & 0.67 \\
\hline EE: inflow & $30 \%$ & 0.71 & IT: inflow & $16 \%$ & 0.65 \\
\hline LK: inflow & $1 \%$ & 0.71 & MX: inflow & $15 \%$ & 0.64 \\
\hline RO: inflow & $14 \%$ & 0.71 & ZA: outflow & $5 \%$ & 0.63 \\
\hline
\end{tabular}

*First two letters indicate country using ISO 3166-1 alpha-2 code. 
Table 8. Capital Flows with a Significant Degree of Concordance*

\begin{tabular}{|c|c|c|c|c|c|}
\hline \multicolumn{6}{|c|}{ Quarterly flows } \\
\hline & $\begin{array}{c}\% \text { of variance } \\
\text { explained }\end{array}$ & $\begin{array}{c}\text { Concordance } \\
\text { index }\end{array}$ & & $\begin{array}{c}\% \text { of variance } \\
\text { explained }\end{array}$ & $\begin{array}{c}\text { Concordance } \\
\text { index }\end{array}$ \\
\hline NO: PI E inflow & $29 \%$ & 0.87 & US: PI D outflow & $36 \%$ & 0.69 \\
\hline IL: OI outflow & $37 \%$ & 0.86 & AT: PI E inflow & $21 \%$ & 0.69 \\
\hline US: PI E outflow & $10 \%$ & 0.85 & CR: DI inflow & $0 \%$ & 0.69 \\
\hline HU: PI D inflow & $15 \%$ & 0.83 & CR: PI D outflow & $5 \%$ & 0.69 \\
\hline DE: PI D outflow & $30 \%$ & 0.82 & BG: Ol outflow & $0 \%$ & 0.69 \\
\hline DE: PI E outflow & $22 \%$ & 0.82 & BR: Ol outflow & $7 \%$ & 0.69 \\
\hline KZ: PI D inflow & $6 \%$ & 0.81 & TH: Ol outflow & $8 \%$ & 0.69 \\
\hline CL: OI outflow & $27 \%$ & 0.81 & ES: DI outflow & $2 \%$ & 0.68 \\
\hline HU: PI D outflow & $1 \%$ & 0.77 & AT: PI D inflow & $0 \%$ & 0.68 \\
\hline BR: PI E inflow & $49 \%$ & 0.77 & AU: PI D inflow & $35 \%$ & 0.68 \\
\hline CZ: PI E outflow & $10 \%$ & 0.77 & FI: PI E inflow & $2 \%$ & 0.68 \\
\hline IN: PI inflow & $46 \%$ & 0.76 & GR: PI E inflow & $10 \%$ & 0.68 \\
\hline CN: OI inflow & $21 \%$ & 0.76 & FR: PI E outflow & $11 \%$ & 0.68 \\
\hline DE: DI outflow & $8 \%$ & 0.75 & NO: OI inflow & $1 \%$ & 0.68 \\
\hline US: DI outflow & $14 \%$ & 0.75 & MY: DI inflow & $6 \%$ & 0.68 \\
\hline IT: PI E inflow & $6 \%$ & 0.75 & SI: PI D inflow & $26 \%$ & 0.68 \\
\hline DK: PI E outflow & $22 \%$ & 0.75 & EE: PI E outflow & $12 \%$ & 0.68 \\
\hline FI: PI E outflow & $38 \%$ & 0.75 & MY: PI E outflow & $3 \%$ & 0.68 \\
\hline IT: PI E outflow & $32 \%$ & 0.75 & KR: OI inflow & $23 \%$ & 0.68 \\
\hline IL: OI inflow & $15 \%$ & 0.75 & KR: Ol outflow & $2 \%$ & 0.68 \\
\hline US: OI inflow & $25 \%$ & 0.75 & AU: PI D inflow & $21 \%$ & 0.67 \\
\hline EE: DI outflow & $20 \%$ & 0.75 & CA: Ol inflow & $1 \%$ & 0.67 \\
\hline TR: DI outflow & $1 \%$ & 0.75 & AT: Ol outflow & $2 \%$ & 0.67 \\
\hline NZ: PI D inflow & $32 \%$ & 0.74 & SE: Ol outflow & $0 \%$ & 0.67 \\
\hline US: PI E inflow & $18 \%$ & 0.74 & BR: DI inflow & $0 \%$ & 0.67 \\
\hline AT: PI E outflow & $18 \%$ & 0.74 & SI: PI D inflow & $4 \%$ & 0.67 \\
\hline AU: PI E outflow & $44 \%$ & 0.74 & BG: PI D outflow & $1 \%$ & 0.67 \\
\hline CA: PI E outflow & $7 \%$ & 0.74 & CN: PI D outflow & $2 \%$ & 0.67 \\
\hline AU: Ol outflow & $1 \%$ & 0.74 & AR: PI E outflow & $18 \%$ & 0.67 \\
\hline LV: DI inflow & $23 \%$ & 0.74 & HU: PI E outflow & $7 \%$ & 0.67 \\
\hline HR: PI E outflow & $15 \%$ & 0.74 & MY: Ol outflow & $20 \%$ & 0.67 \\
\hline US: PI D inflow & $19 \%$ & 0.73 & IL: DI outflow & $0 \%$ & 0.65 \\
\hline SE: PI D outflow & $37 \%$ & 0.73 & JP: PI E inflow & $20 \%$ & 0.65 \\
\hline FR: Ol inflow & $25 \%$ & 0.73 & BR: PI D inflow & $15 \%$ & 0.65 \\
\hline US: Ol outflow & $26 \%$ & 0.73 & LT: PI D inflow & 6 & 0.65 \\
\hline PL: DI inflow & $17 \%$ & 0.73 & TR: OI inflow & $9 \%$ & 0.65 \\
\hline TR: PI D inflow & $9 \%$ & 0.73 & FI: PI D outflow & $6 \%$ & 0.64 \\
\hline $\mathrm{CN}$ : PI E inflow & $3 \%$ & 0.73 & DE: PI E inflow & $3 \%$ & 0.64 \\
\hline IN: OI inflow & $11 \%$ & 0.73 & SE: PI E outflow & $2 \%$ & 0.64 \\
\hline LK: OI inflow & $6 \%$ & 0.73 & NZ: OI outflow & $1 \%$ & 0.64 \\
\hline SE: DI inflow & $0 \%$ & 0.71 & PL: PI E inflow & $10 \%$ & 0.64 \\
\hline FR: OI outflow & $16 \%$ & 0.71 & BR: PI E outflow & $1 \%$ & 0.64 \\
\hline BR: DI outflow & $1 \%$ & 0.71 & HR: Ol outflow & $1 \%$ & 0.64 \\
\hline CO: PI D outflow & $8 \%$ & 0.71 & ES: PI E inflow & $2 \%$ & 0.63 \\
\hline KZ: PI E outflow & $12 \%$ & 0.71 & IT: PI D inflow & $6 \%$ & 0.62 \\
\hline LV: PI E outflow & $12 \%$ & 0.71 & KR: DI inflow & $0 \%$ & 0.62 \\
\hline FR: PI E inflow & $5 \%$ & 0.70 & DK: DI inflow & $0 \%$ & 0.61 \\
\hline JP: OI outflow & $19 \%$ & 0.70 & SK: PI D outflow & $0 \%$ & 0.61 \\
\hline EE: DI inflow & $12 \%$ & 0.70 & PT: DI inflow & $0 \%$ & 0.60 \\
\hline LV: DI outflow & $13 \%$ & 0.70 & GR: OI outflow & $4 \%$ & 0.39 \\
\hline SI: PI E inflow & $3 \%$ & 0.70 & FI: PI D inflow & $0 \%$ & 0.36 \\
\hline LT: PI E outflow & $18 \%$ & 0.70 & NZ: PI E inflow & $1 \%$ & 0.36 \\
\hline CZ: Ol inflow & $1 \%$ & 0.70 & ID: OI outflow & $0 \%$ & 0.36 \\
\hline EE: Ol inflow & $24 \%$ & 0.70 & AR: Ol outflow & $0 \%$ & 0.31 \\
\hline SI: OI outflow & $8 \%$ & 0.70 & SK: DI inflow & $5 \%$ & 0.23 \\
\hline ES: PI D inflow & $18 \%$ & 0.69 & & & \\
\hline
\end{tabular}

*First two letters indicate country using ISO 3166-1 alpha-2 code.

** DI - direct investment; PI D - portfolio investment in debt; PI E - portfolio investment in equity; OI - other investment. 


\section{APPENDIX B. FIGURES}

(a) Global Factors in Annual Data

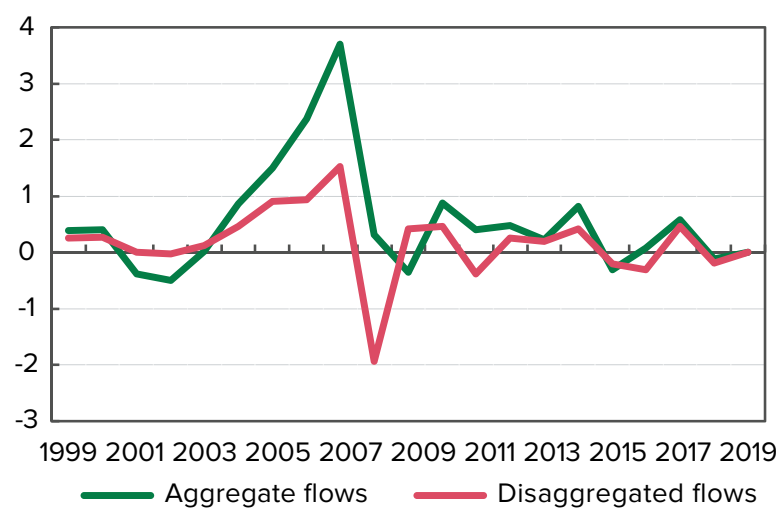

(c) Global Factors in Aggregate Flows

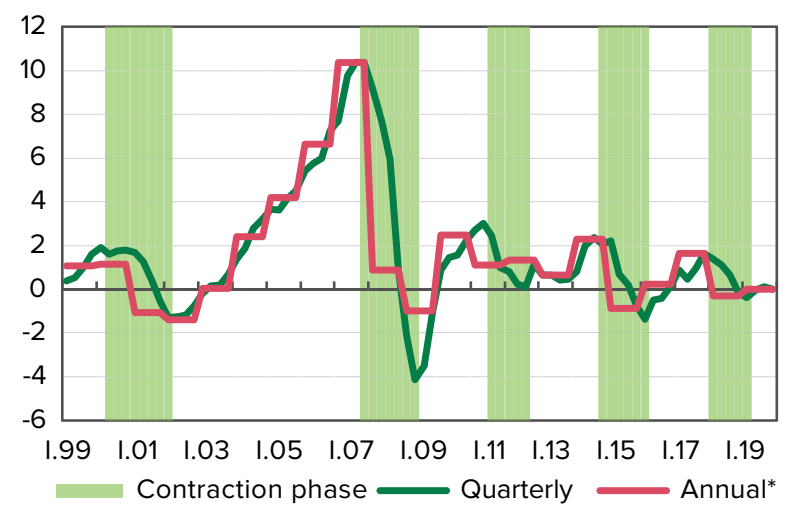

Figure 7. Global Factors in Data

*Scaled by 2.8 and 4.3 , respectively, for visibility.

(a) Annual Aggregated Flows

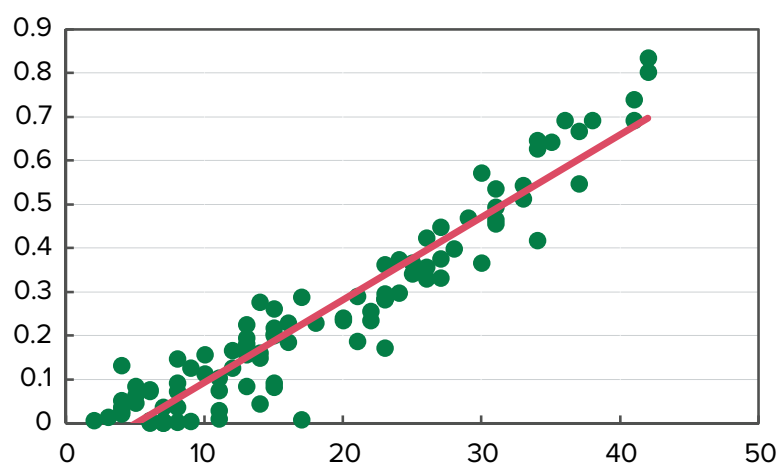

(c) Quarterly Aggregated Flows

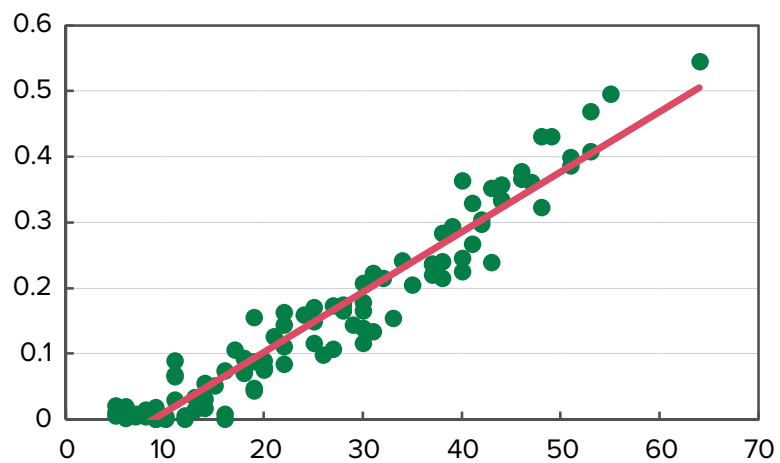

(b) Global Factors in Quarterly Data

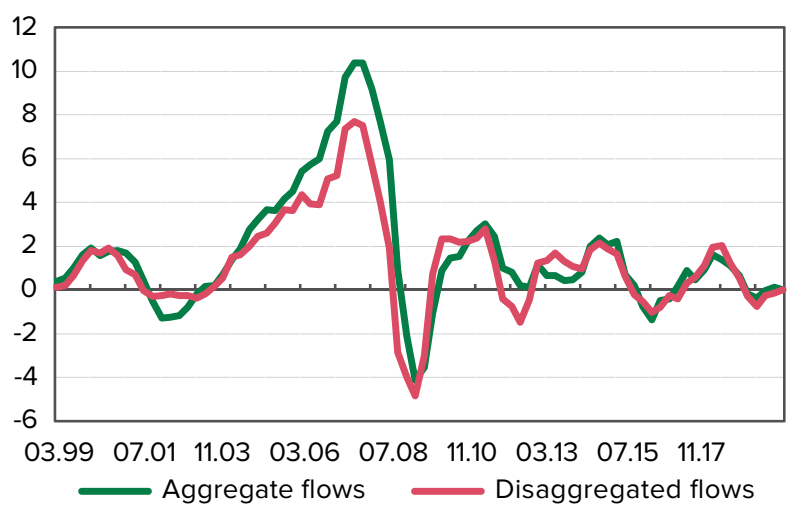

(d) Global Factors in Disaggregated Flows

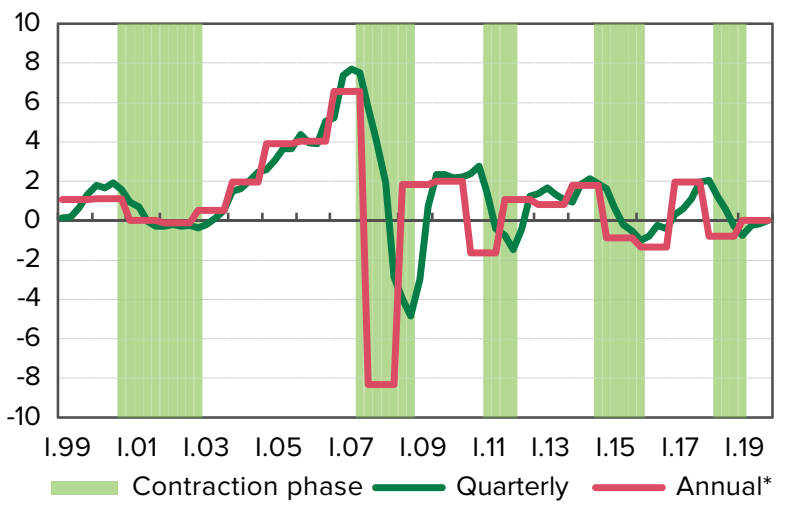

(b) Annual Disaggregated Flows

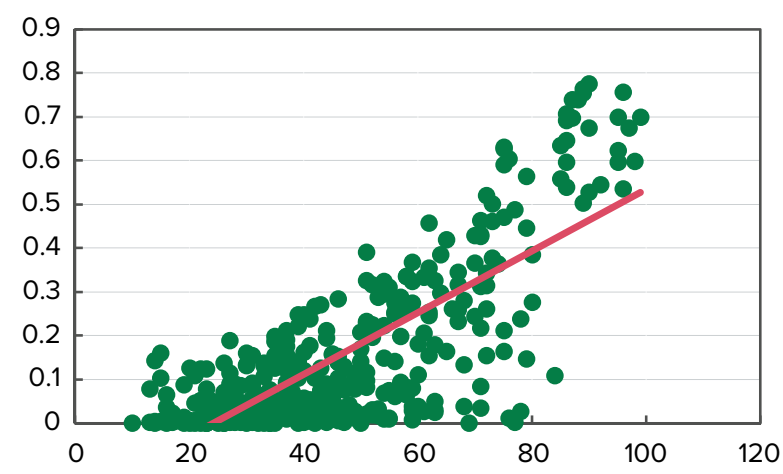

(d) Quarterly Disaggregated Flows

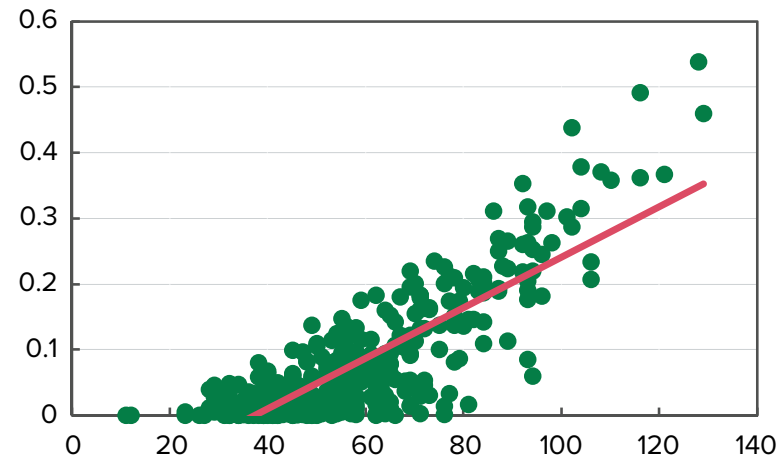

Figure 8. Linear Relationship Between the Share of Variance Explained and Number of Significant Pairwise Correlations*

*Dots represent capital flows, each particular flow can have 99 pairwise correlations in aggregated data and 395 pairwise correlations in disaggregated data. 


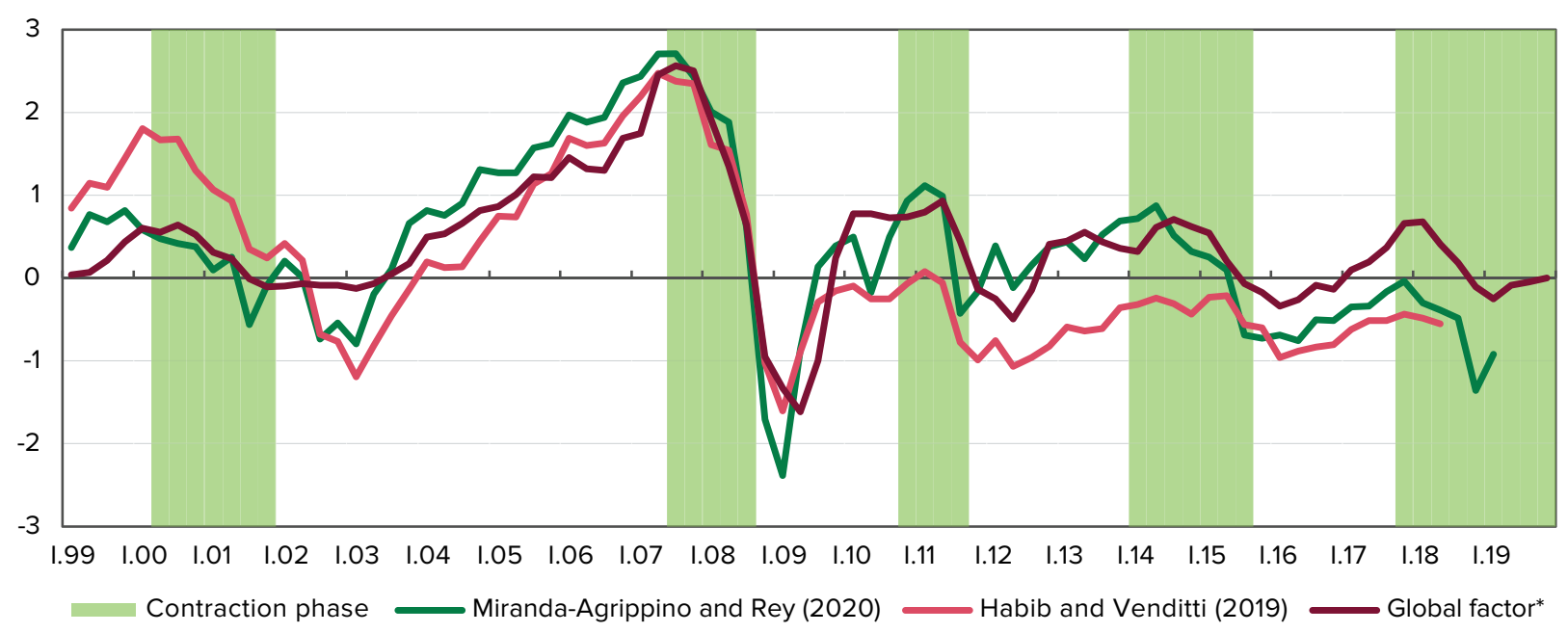

Figure 9. Estimates of the Global Financial Cycle

* The global factor from disaggregated flows; scaled by $1 / 3$ for visibility.

(a) Concordance Indices for Aggregate Flows

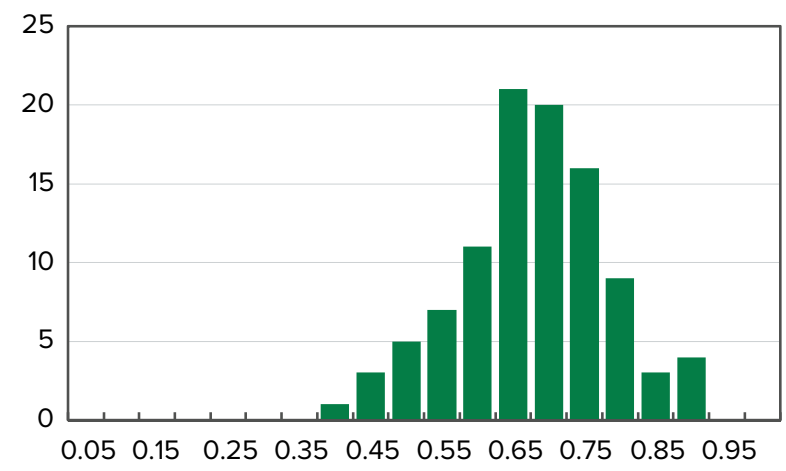

(b) Concordance Indices for Disaggregated Flows

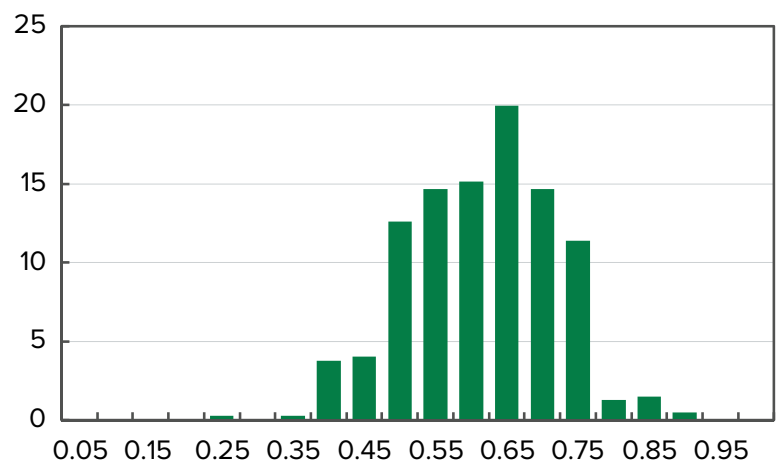

Figure 10. Distributions of Concordance Indices, Calculated using Aggregate Capital Flows (left) and Capital Flows, Disaggregated by Type (right) 
(a) Global Factor

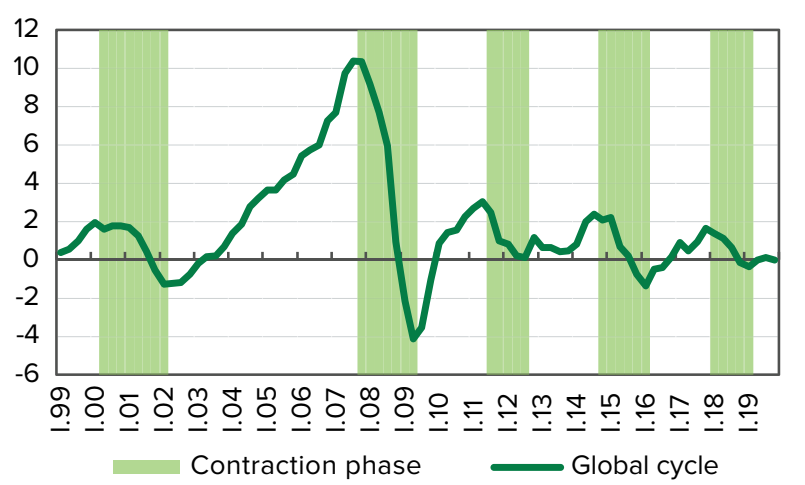

(c) Capital Inflows in Hungary

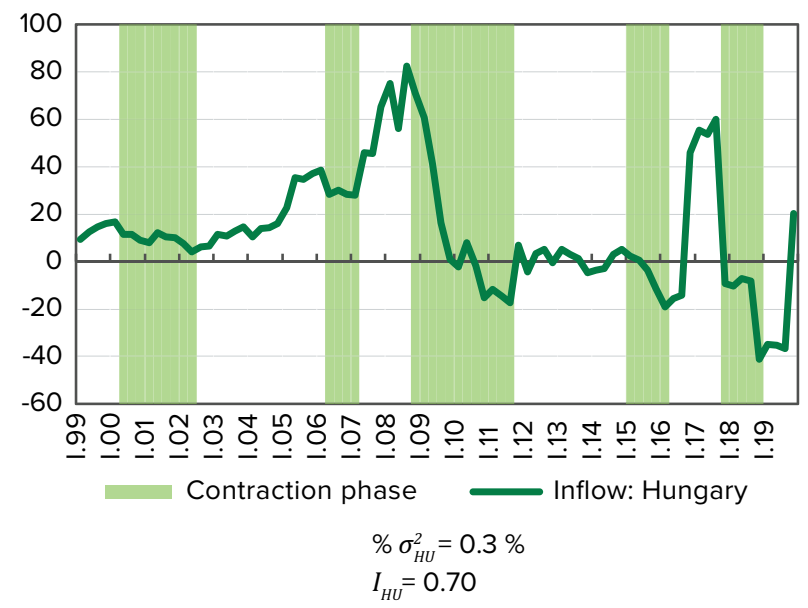

(b) Capital Outflows from Republic of Korea

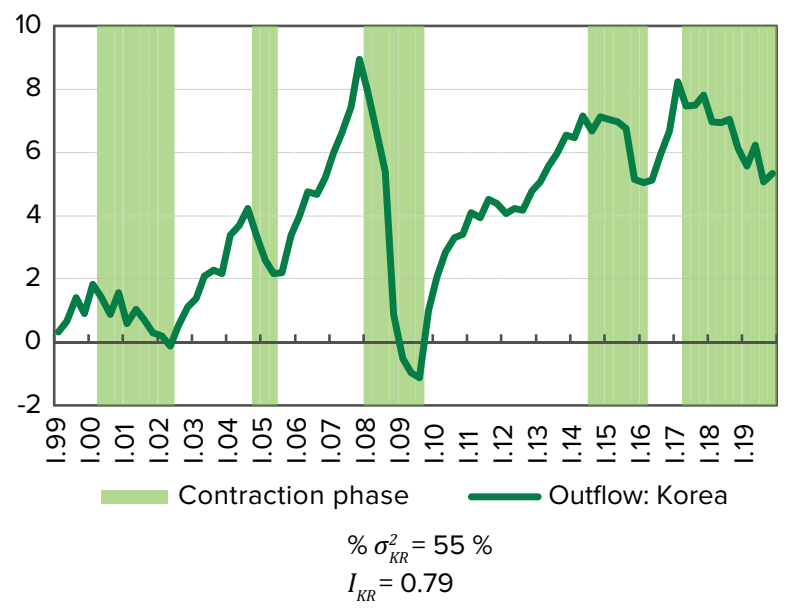

(d) Capital Inflows in Peru

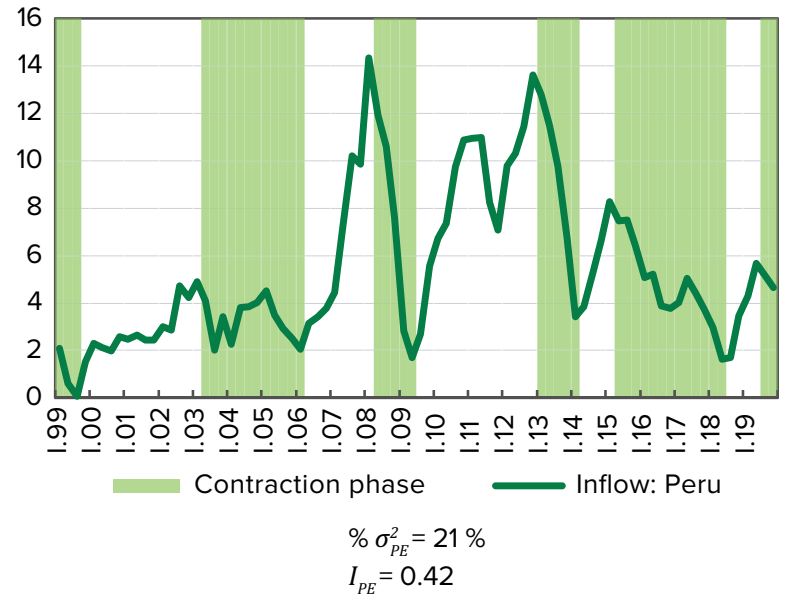

Figure 11. Cyclical Pattern in Global Factor and Selected Capital Flows* $* \% \sigma_{i}^{2}$-share of variance explained; $I_{i}-$ concordance index. 